\title{
Surgical Treatment of Developmental Dysplasia of the Hip in Children Three to Five Years of Age
}

\author{
Mohammed AbdelFattah Sebae, MD, Reda Hussein ElKady, MD \\ Lecturer of Orthopedic Surgery, Faculty of Medicine, Zagazig University, Egypt. \\ ymkhairy@medicine.zu.edu.eg \\ yousufmmkh@gmail.com
}

\section{Abstract}

Background: The neglected DDH with adaptive changes in bone and soft tissue is difficult to treat and can lead to permanent disability. The aim of treatment of these cases to establish normal anatomy of the femur and acetabulum to promote normal development of the hip.

Aim of the Work: The aim of this study is to evaluate of the results of one-stage surgical treatment of DDH in children between 3-5 years of age.

Patients and Methods: A prospective study on 36 children (40 hips) presented by DDH at age between 3-5 years old, 16 hips were Tonnis grade III and 24 hips were grade IV. Open reduction, derotation femoral osteotomy with shortening was done for all hips, Varusangulation for excessive valgus was add to the osteotomy in 16 hips (40\%), and Degapel vicosteotomy was added to femoral osteotomy in 24 hips (60\%). Post operatively hip spica was done for all the patients for twelve weeks.

Results: The mean follow- up period was 40 months (range 24 - 60 months). Clinically, according to Mc Kay system, the outcome was excellent for 20 hips (50\%) were, good in 14 hips (35\%), fair in 4(10\%), and poor in 2 hip s (5\%). Radiologically, the Severin's classification criteria for 22 hips (55\%) were excellent, in 12 hips (30\%) were good, fair in $4(10 \%)$, and were poor in 2 (5\%).

Conclusion: One stage hip reconstruction operation is a good approach to treat the cases with late presented developmental dysplasia of hip (DDH). A stable concentric reduction can be achieved which help in remodeling of the acetabulum and stable concentric reduction of the dislocated hip. Tonnis grade III dislocation of DDH is risky for residual acetabular dysplasia and subluxation after one stage hip reconstruction.

Keywards: surgical, treatment, developmental, dysplasia, hip,

\section{INTRODUCTION}

The neglected DDH with adaptive changes in bone and soft tissue is difficult to treat and can lead to permanent disability. [1]. Residual acetabulardy splasia and hip subluxation in children result in premature arthritis of hip in young adults [2]. The aim of treatment of these cases is to establish normal anatomy of the femur and acetabulum to promote normal development of the hip [3]. Treatment with one-stage procedure (open reduction, capsulorrhaphy, and femoral osteotomy with or without shortening) is preferred by many authors. In those late presenting children, a pelvic osteotomy is needed to achieve a stable concentric reduction [4-6]. The Dega osteotomy is one of the commonly used osteotomies in the management of DDH. Dega described two different types of incomplete trans-iliac osteotomies [7,8].

The purpose of this study is evaluation of the results of one-stage hip operation in DDH presented between 3-5 years of age. 


\section{Patients ANd Methods}

A prospective study on 36 children (40 hips) presented by DDH at age between 3-5 years old, 16 hips were Tonnis [9] grade III and 24 hips were grade IV. Open reduction, derotation femoral osteotomy with shortening was done for all hips, Varus angulation for excessive valgus was add to the osteotomy in 16 hips (40\%), and Dega pelvic osteotomy was added to femoral osteotomy in 24 hips (60\%). Postoperatively hip spica was done for all the patients for twelve weeks.

There were 22 girls (28 hips) and 14 boys (12 hips). Dislocation of the left hip in 20 patients; 12 patients had dislocation of the right and 4 girls had bilateral dislocation. Open reduction with shortening and derotation of the femur was done for all hips, Varusangulation for excessive valgus was add to the osteotomyin 16 hips (40\%), and Degapel vicosteotomy was performed in 24 hips (60\%). Post operatively hip spica was done for all the patients for twelve weeks.

\section{Preoperative Evaluation}

According to Tonnis classification system [9], there were eighteen hips Tonnis grade III and 22 hips were grade IV [Table 1]. Radiological evaluation of reduction included the acetabular index (AI) [10], the center-edge angle of Wiberg (CEA) [11], the migration percentage of Reimers (MI) [12], Shenton line disruption, the femoral neck shaft angle, and evaluation of the grade of the femoral head avascular necrosis (AVN) according to Bucholz-Ogden classification system [13].

\section{Operative Procedure}

The mean operative time was $120 \pm 18 \mathrm{~min}$. range (90-145).The mean operative blood loss was $250 \pm 49$ (range 150-350) $\mathrm{ml}$. The mean follow -up period was 40 months (range $24-60$ months after surgery.

Immediately after surgery, a double spica cast was applied in $30^{\circ}$ of flexion and $30^{\circ}$ of abduction with $20^{\circ}$ internal rotation of the hips. Plain x-rays were done to evaluate reduction of the femoral head into the true acetabulum. Three months postoperative, an abduction orthosis was used at night for 2 months. Follow up radiographs were taken every month for the first 3 months after spica followed by every 3 months until the end of the first year, and every 6 months later.

\section{Statistical Analysis}

The Statistical Package for the Social Sciences (SPSS version 20.0) software was used for analysis. According to the type of data qualitative represent as number and percentage, quantitative continues group represent by mean $\pm \mathrm{SD}$, comparison between paired quantitative parametric data by Paired $t$ test.

\section{RESULTS}

The mean follow- up period was 40 months (range 24 - 60 months). Clinically, according to McKay system [14], the outcome was excellent (achieving Stable painless hip)for 20 hips (50\%) were, good (there was a slight limp, and limitation of last degrees of movement) in 14 hips (35\%), fair (with limp, positive trendelenburg sign limited abduction $\left(10^{\circ}-25^{\circ}\right)$ and internal rotation in flexion (0-10), exhibit radiological coxa plana due to AVN of the femoral head) in 4(10\%), and poor (unstable, and had residual subluxation at latest follow-up radiographs) in 2 hips (5\%).

\section{RADIOGRAPHIC RESULTS}

The preoperative, the early postoperative and latest follow-up radiographs were used to measure the acetabular index (AI), the center-edge angle of Wiberg (CEA), the migration percentage of Reimers (MI), Shenton line disrupation, and the femoral neck shaft angle. In all hips but two, the acetabular index was improved at the latest follow-up examination, in those two hips, the femoral head was subluxed. The mean preoperative AI was $43^{\circ} \pm 8.5$, and at the end of follow -up it was reduced to an average $22^{\circ} \pm 5.6$ [range $20^{\circ}-30^{\circ}$ ]. 
Surgical Treatment of Developmental Dysplasia of the Hip in Children Three to Five Years of Age

The preoperative CEA was negative in all patients. In all hips except two, the mean postoperative center- edge angle was improved with average $29^{\circ} \pm 8.6$ [range $20^{\circ}-50^{\circ}$ ] at the end of follow-up period. In two hips with poor results the CEA was $\left[10^{\circ}\right]$ and the femoral head was subluxed. The mean postoperative migration percentage described by Reimers [- $0.22 \pm 0.06]$, and at the end of follow -up the mean MI was [-0.19 \pm 0.04$]$. The Shenton line was intact in 38 hips. The neck shaft angle was increased from an average of $118^{\circ} \pm 12.8$ postoperatively to $126^{\circ} \pm 14.4$ at the latest follow-up examination [Fig. 1, 2, 3]. The Severin's classification [15] criteria for 22 hips (55\%) were excellent, in 12 hips (30\%) were good, fair in 4 (10\%), and were poor in 2 hips (5\%), both patients had Tonnis grade III hip dislocation.

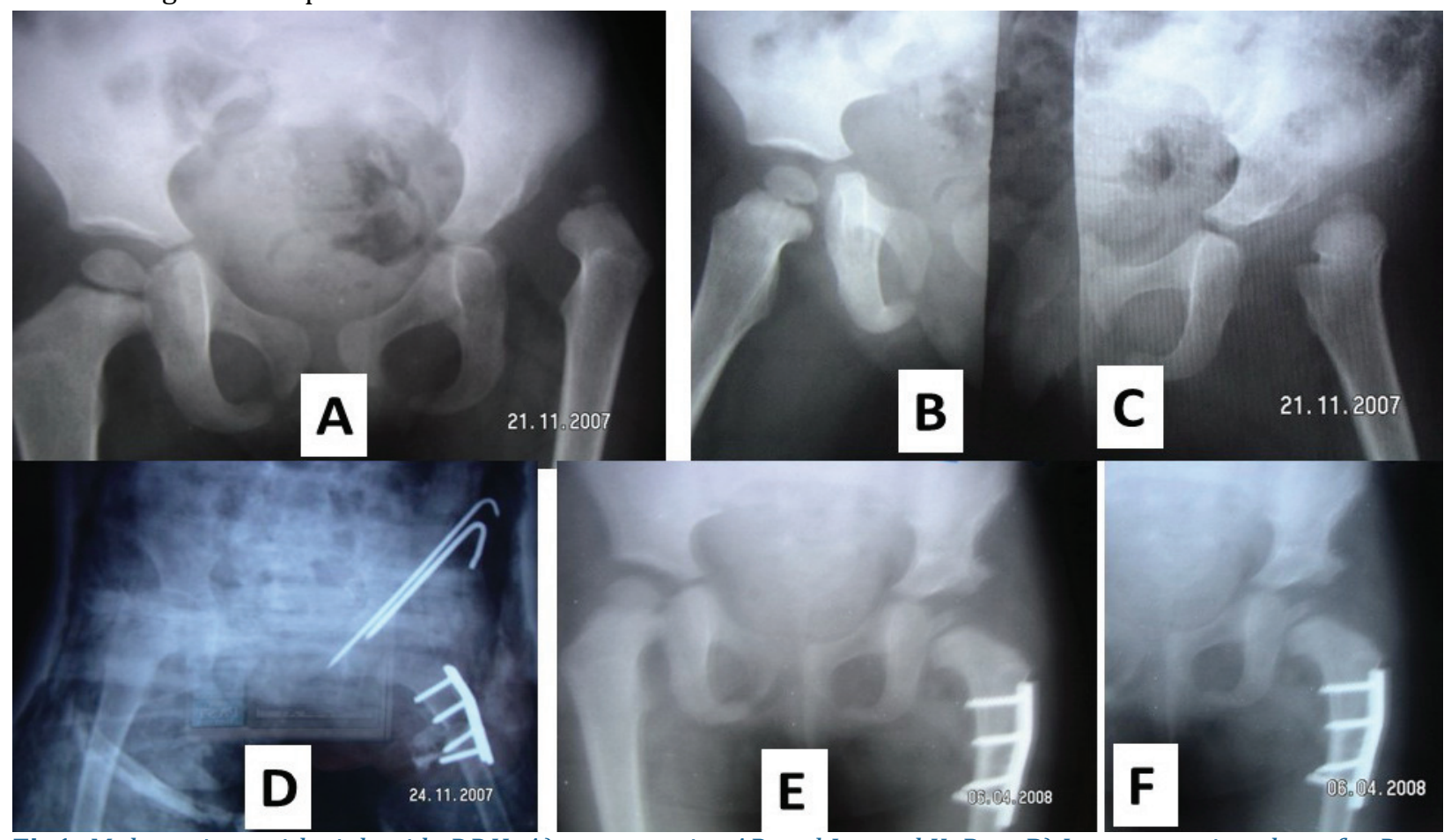

Fig1. Male patient with right side DDH: A) preoperative AP and Lateral X-Ray; B) Intraoperative photo for Dega osteotomy; C) Intraoperative radiograph for the osteotomy and reduction; D) postoperative $C T$ scan for reduction of hip joint.
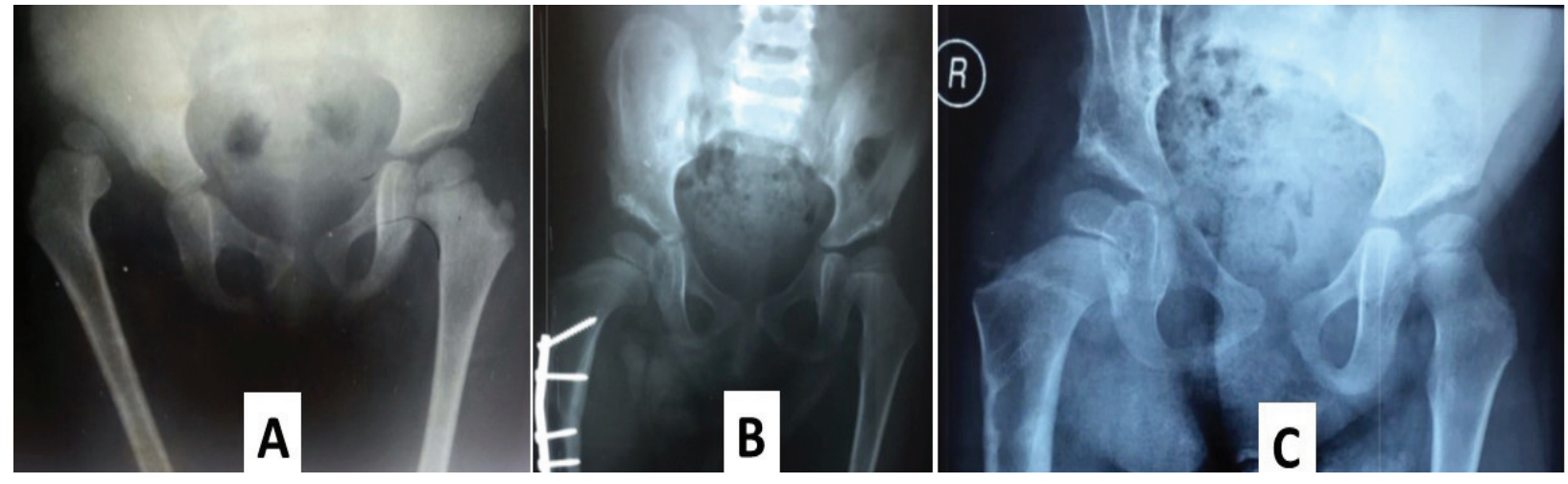

Fig2. Female child 3years and 5 months old; she had right DDH, (A) Preoperative radiograph anteroposterior (AP) view. (B) Early postoperative radiograph AP view after one- stage hip reconstruction, reveal containment of the femoral head. (C) Final follow -up radiograph AP view 2 years postoperatively with excellent clinical and radiographic outcome. 


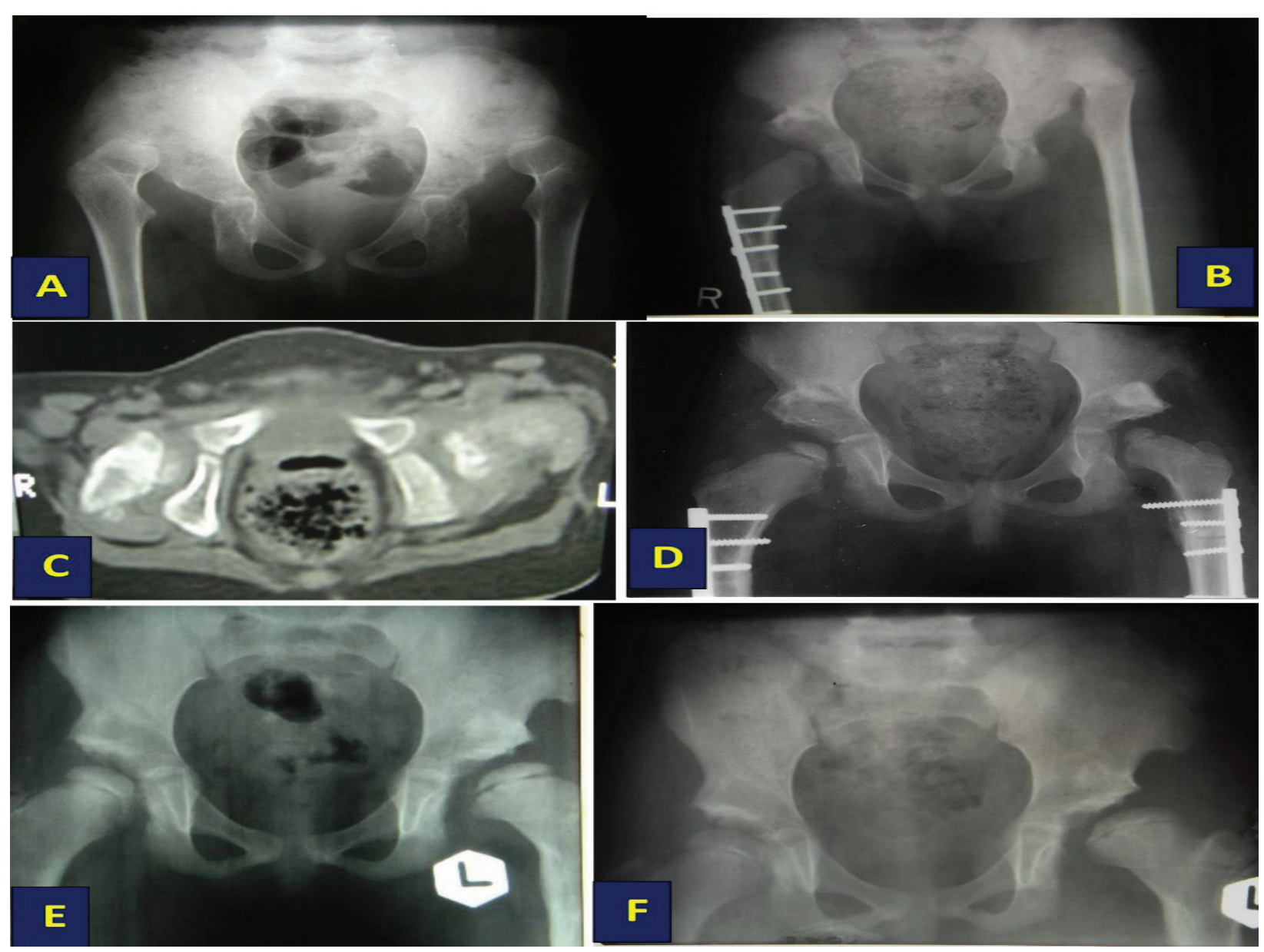

Fig3. female patient with bilateral DDH : A) Preoperative X-ray; B) postoperative right side operated; C) C-T scan after reduction of right side; D) postoperative with 2 sides operated; E) X-ray after 3 years; F) X-ray after 6 years

\section{Complications}

In 3 patients, superficial infection of the wound was treated by local wound care and oral antibiotics. Injury of the lateral cutaneous nerve of the thigh was found in 2 patients. Supracondylar femoral fractures found in 2 patients after removal of the spica casts, and were treated conservatively and have no effect on the final results. Residual subluxation in two hips was found at the latest follow-up. There was no significant limb length discrepancy in cases with femoral shortening after two years or more. According to Bucholz and Ogden [13], four hips were classified as type $1 \mathrm{AVN}$. At follow-up, only mild loss of height of the epiphysis was noted in these cases [Table --].

Table1. DDH Types according to Tonnis

\begin{tabular}{|l|l|l|}
\hline Grade & Criteria & Number of hips (\%) \\
\hline$I$ & Capital femorale piphysis below Helgereinermedial to Perkins line & $0(0.0)$ \\
\hline II & $\begin{array}{l}\text { Capital femorale piphysis lateral to Perkinsline, but below the level of } \\
\text { the superior acetabularrim }\end{array}$ & $0(0.0)$ \\
\hline III & Capital femorale piphysis at the level of the superior acetabularrim & $16(40 \%)$ \\
\hline$I V$ & Capital femorale piphysis above the level of the superior acetabularrim & $24(60 \%)$ \\
\hline
\end{tabular}

American Research Journal of Orthopedics and Traumatology

Page 4 
Surgical Treatment of Developmental Dysplasia of the Hip in Children Three to Five Years of Age

Table2. Clinical assessment according to McKay classification

\begin{tabular}{|l|l|l|}
\hline Grade & Criteria & Number of hips (\%) \\
\hline Excellent & $\begin{array}{l}\text { Stable, painless hip no limp, negative Trendelenburg sign and a } \\
\text { fullrange of movement }\end{array}$ & $20(50 \%)$ \\
\hline Good & $\begin{array}{l}\text { Stable, painless hips light limp, negative Trendelenburg sign } \\
\text { and a slight decrease in range of movement }\end{array}$ & $14(35 \%)$ \\
\hline Fair & $\begin{array}{l}\text { Stable, painless hip, limp, positive Trendelenburg sign and } \\
\text { limitation of movement }\end{array}$ & $4(10 \%)$ \\
\hline Poor & Unstable or painful hip, or both; positive Trendelenburg sign & $2(5 \%)$ \\
\hline
\end{tabular}

Table3. Radiographic assessment according to Severin's classification.

\begin{tabular}{|l|l|l|l|}
\hline \multicolumn{1}{|c|}{ Class } & \multicolumn{1}{|c|}{ Description } & $\begin{array}{l}\text { Center Edgeangle } \\
\text { (degrees) }\end{array}$ & Number of hips (\%) \\
\hline Class1[excellent] & Normal appearance & $\geq 15(5-13 y e a r s)$ & $22(55)$ \\
\hline Class2[good] & $\begin{array}{l}\text { Mild deformity of the femoralhead and neck } \\
\text { or the acetabulum }\end{array}$ & $\geq 15(5-13 y e a r s)$ & $12(30)$ \\
\hline Class3[fair] & $\begin{array}{l}\text { Dysplasia or moderated eformity of the } \\
\text { femoralhead and neck or acetabulum, or both }\end{array}$ & $<15(5-13 y e a r s)$ & $4(10)$ \\
\hline Class4[poor] & Subluxation of the femoralhead & - & $2(5)$ \\
\hline Class5[failure] & $\begin{array}{l}\text { Articulation of the femoralhead with the false } \\
\text { acetabulum }\end{array}$ & - & - \\
\hline Class6[failure] & Redislocation. & - & - \\
\hline
\end{tabular}

\section{DISCUSSION}

The aim of treatment of DDH in children is to gain concentric reduction of the head of the femur into the true acetabulum $[3,16-18]$. The age at operation was an important risk factor for treatment failure and management of late presented children is a real challenge. Concentric reduction may be obstructed by soft tissue contracture with excessive compression on the femoral head. Poor motion of the hip joint and a vascular necrosis of the femoral head may be produced from forced reduction. Many authors have reported that femoral shortening reduced the risk of osteonecrosis of the femoral head as well as facilitating reduction, and improve motion of the joint. Dysplastic acetabulum and femoral head flattening that is aggravated in older children, result in difficult reduction [19-21]. Many authors have reported that a one-stage hip reconstruction is safe and effective method for treatment of late-diagnosed DDH [21-23].

In this work 36 patients [40 hips] complain of DDH with age ranged from three to five years have been treated with a one-stage hip reconstruction. The mean follow-up period was 40 months. Open reduction with shortening and derotation of the femur was done for all hips, Varus angulation for excessive valgus was add to the osteotomy in 20 hips (50\%), and Dega pelvic osteotomy was performed in 24 hips (60). Femoral and Pelvic osteotomies were decided according to age, grade of dislocation, acetabular index and the intra operative test of stability that was applied and the stable position for hip reduction achieved to perform appropriate osteotomy.

Many authors have reported the functional and radiographic results of a one-stage hip reconstruction for DDH. Karakas et al. [20] obtained 67\% clinically and 65\% radio graphically good or excellent results according to McKay [14] and Severin [15] classifications in 55 hips with a one-stage hip reconstruction. Forlin et al. [24] presented a series of 20 children (24 hips) with DDH treated by a one-stage hip reconstruction who were 4 and 12 years of age. They obtained excellent or good results in Seventeen (70\%) of those hips according to 
the McKay and Sever in classifications. The poor results were reported in patients older than 7 years at the time of hip reconstruction. Umer et al. [22] presented a series of 23 patients (29 hips) treated by one stage hip reconstruction. The average age of the patients was 6.84 years. The mean follow-up period was 19.6 months, excellent or good results were achieved in 25 (86\%) hips according to the Mc Key classification [14]. Ganger et al. [25] obtained excellent or good results in $80 \%$ of hips after treatment by one- stage hip reconstruction according to the Sever in classification [15]. The mean follow-up period was 3.5 years. Galpin et al. [19] obtained good results in $75-85 \%$ of patients after radiographic and clinical evaluation. These previous studies have shown that the better results were obtained when the patients were younger at the time of surgery.

In this series, 40 hips with DDH in children 3-5 years old treated by one-stage operation, 31 hips (85 \%) achieved good or excellent results according to McKay clinical classification, and 30 hips (85\%) achieved good or excellent according to Sever in radiographic classification after a mean follow up of forty months. Our results were comparable to the results of the previous studies. Many studies reported that AVN of the femoral head is one of the main complications associated with treatment of DDH. Our results revealed that 4 hips (10\%) had avascular necrosis according to the Bucholz and Ogden classification [13].Many authors reported that femoral shortening and adequate immobilization in the hip spica might avoid AVN [14, 25, and 26]. In this study, femoral shortening and stable reduction during surgery and immobilization in hip spica in position $30^{\circ}$ of flexion and $30^{\circ}$ of abduction with $20^{\circ}$ internal rotation for 12 weeks were required.

It is important that older children with DDH should be early diagnosed and managed by one- stage hip reconstruction for a satisfactory result. Subluxation and residual acetabular dysplasia are inevitable complications during management of DDH. Many authors have been reported that the incidence of avascular necrosis after open reduction is 0-8\% [27-29]. Bilateral DDH, femoral head enlargement, increased anteversion, and inappropriate pelvic osteotomy is risky for subluxation and residual acetabular dysplasia [17,29-31]. In the present study, 2 patients had subluxation with residual acetabular dysplasia (5\%) and required another surgical intervention. These complications occurred in patients with DDH Tonnis grade III. The results proposed that DDH Tonnis grade III was risky for residual acetabular dysplasia and subluxation after one-stage hip reconstruction. These complications may result from excessive compression of the femoral head on the edge of the acetabulum in patients with Tonnis grade III DDH. The excessive compression result in poor acetabular development with the risk of residual acetabular dysplasia and subluxation after hip reconstruction. The data were comparable to the former studies $[28,30]$.

\section{CONCLUSION}

One stage hip reconstruction operation is a good approach to treat the cases with late presented developmental dysplasia of hip (DDH). A stable concentric reduction can be achieved which help in remodeling of the acetabulum and stable concentric reduction of the dislocated hip. Tonnis grade III dislocation of DDH is risky for residual acetabular dysplasia and subluxation after one stage hip reconstruction.

\section{REFERENCES}

1. Shipman, S.A., Helfand, M., Moyer, V.A., Yawn, B.P. (2006). Screening for developmental dysplasia of hip: a systemic review for the US Preventive Services Task Force. Pediatrics., 117, 557-576.

2. El-Sayed M. M. H.; Hegazy M; Nasef M.; Abdelatif M A. E, ElSobky T.; NaderS. : Dega osteotomy for the management of developmental dysplasia of the hip in children aged 2-8 years: results of 58 consecutive osteotomies after 13-25 years of follow-up; J Child Orthop (2015); 9: 191-198.

3. Guaracy CF, Alceu GC, Helencar I, Carneiro MO, FranceseNeto J, Canesin AC: Surgical treatment of the congenital dislocation of the hip after walking age: open reduction and Salter's osteotomy. ActaOrtop Bras. 2003; 11(1):42-7.

American Research Journal of Orthopedics and Traumatology

Page 6 
Surgical Treatment of Developmental Dysplasia of the Hip in Children Three to Five Years of Age

4. Grudziak JS, Ward WT: Dega osteotomy for the treatment of congenital dysplasia of the hip. J Bone Joint Surg Am(2001); 83(A6):845-854.

5. Baloch, N., Saqlain, A.H., Hashmi, I., Javaid, A., Hussain, A. (2004). Acetabuloplasty and total hip replacement in neglected bilateral developmental dysplasia of hip joint (DDH). J. Surg. Pak., 9, 45-47.

6. Wedge JH, Thomas SR, Salter RB.: Outcome at forty-five years after open reduction and innominate osteotomy for late-presenting developmental dysplasia of the hip. Surgical technique. J Bone Joint Surg Am. 2008; 90 Suppl 2 (Pt 2):238-53.

7. Al-Ghamdi A, Rendon J, Al-Faya F, Saran N, Benaroch T, HamdyR: Dega osteotomy for the correction of acetabular dysplasia of the Hip: a radiographic review of 21 cases. J Pediatr Orthop (2012); 32:113-120.

8. Enan A.; Abo-hegy M.; Hammad W. (2013): Surgical treatment of the late - presenting developmental dislocation of the hip after walking age; ActaOrtop Bras. 2013; 21(5): 276-280.

9. Tonnis D. (1987). Congenital dysplasia and dislocation of the hip in children and adults. Springer, New York.

10. Hilgenreiner H. (1925). ZurFru "hdiagnose und Fru "hbehandlung der angeborenenHu"ftgelenksverrenkun g. Med Klin 21(1385-8): 1425-1429.

11. Wiberg G. (1939). Studies on dysplastic acetabula and congenital subluxation of the hip joint. With special reference to the complication of osteoarthritis. ActaChirScand 83[Suppl 58]:53-68.

12. Reimers J. (1980). The stability of the hip in children. A radiological study of the results of muscle surgery in cerebral palsy. Acta Orthop ScandSuppl 184:1- 100.

13. Bucholz RW, Ogden JA. (1978). Patterns of ischemic necrosis of the proximal femur in nonoperatively treated congenital hip disease. In: The hip: Processings of the Sixth Open Scientific Meatingof the Hip Society. St. Louis: Cv Mosby; pp.43-63.

14. McKay DW. (1974). A comparison of the innominate and the pericapsular osteotomy in the treatment of congenital dislocation of the hip. Clin Orthop Relat Res.; 98:124-32.

15. Severin E. (1941). Contribution to the knowledge of congenital dislocation of the hip joint. Late results of closed reduction and arthrographic studies of recent cases. ActaChirScand 84(Suppl 63):1-142.

16. Wedge JH, Kelley SP. (2012). Strategies to improve outcomes from operative childhood management of DDH. Orthop Clin North Am, 43(3):291-299.

17. Sankar WN, Young CR, Lin AG, Crow SA, Baldwin KD, Moseley CF. (2011). Risk factors for failure after open reduction for DDH: a matched cohort analysis. J Pediatr Orthop, 31(3):232-239.

18. Braatz F, Eidemuller A, Klotz MC, Beckmann NA, Wolf SI, Dreher T. (2014). Hip reconstruction surgery is successful in restoring joint congruity in patients with cerebral palsy: long-term outcome. Int Orthop, 38(11):2237-2243.

19. Galpin RD, Roach JW, Wenger DR, Herring JA, Birch JG. (1989). One-stage treatment of congenital dislocation of the hip in older children, including femoral shortening. J Bone Joint Surg Am, 71(5):734-741.

20. Karakas ES, Baktir A, Argun M, Turk CY. (1995). One-stage treatment of congenital dislocation of the hip in older children. J Pediatr Orthop, 15(3):330- 336.

21. Dogan M, Bozkurt M, Sesen H, Yildirim H. (2005). One-stage treatment of congenital severely dislocated hips in older children through various acetabuloplasty techniques: 22 children followed for 1-5 years. Acta Orthop, 76(2):212-219. 
Surgical Treatment of Developmental Dysplasia of the Hip in Children Three to Five Years of Age

22. Umer, M., Nawaz, H. (2008). Developmental Dysplasia of Hip - Where do we stand. J. Pak. Med. Assoc., 58, 2-4

23. Haidar RK, Jones RS, Vergroesen DA, Evans GA. (1996). Simultaneous open reduction and Salter innominate osteotomy for developmental dysplasia of the hip. J Bone Joint Surg (Br), 78(3):471-476.

24. Salter RB, Dubos JP. (1974). The first fifteen year's personal experience with innominate osteotomy in the treatment of congenital dislocation and subluxation of the hip. Clin Orthop Relat Res, 98:72- 103.

25. Forlin E, Munhoz da Cunha LA, Figueiredo DC. (2006). Treatment of developmental dysplasia of the hip after walking age with open reduction, femoral shortening, and acetabular osteotomy. Orthop Clin North Am, 37(2):149-160.

26. Ganger R, Radler C, Petje G, Manner HM, Kriegs-Au G, Grill F. (2005). Treatment options for developmental dislocation of the hip after walking age. J Pediatr Orthop B, 14(3):139-150.

27. Tonnis D. (1990). Surgical treatment of congenital dislocation of the hip. Clin Orthop Relat Res, 258:33-40.

28. Schoenecker PL, Strecker WB. (1984). Congenital dislocation of the hip in children. Comparison of the effects of femoral shortening and of skeletal traction in treatment. J Bone Joint Surg Am, 66(1):21- 27.

29. Kershaw CJ, Ware HE, Pattinson R, Fixsen JA. (1993). Revision of failed open reduction of congenital dislocation of the hip. J Bone Joint Surg (Br), 75(5):744- 749.

30. Kamath SU, Bennet GC. (2005). Re- dislocation following open reduction for developmental dysplasia of the hip. Int Orthop, 29(3):191-194.

31. Wang TM, Wu KW, Shih SF, Huang SC, Kuo KN: Outcomes of open reduction for developmental dysplasia of the hip. (2013). does bilateral dysplasia have a poorer outcome? J Bone Joint Surg Am, 95(12):1081-1086.

Citation: Mohammed AbdelFattah Sebae, MD, Reda Hussein ElKady, MD. "Surgical Treatment of Developmental Dysplasia of the Hip in Children Three to Five Years of Age". American Research Journal of Orthopedics and Traumatology. 2017; 2(1): 1-8.

Copyright (c) 2017 Mohammed AbdelFattah Sebae, MD, Reda Hussein ElKady, MD. This is an open access article distributed under the Creative Commons Attribution License, which permits unrestricted use, distribution, and reproduction in any medium, provided the original work is properly cited. 